\title{
Mikroalgal Biyoyakıt Araştırmaları için Laboratuar Ölçekli Fotobiyoreaktör Otomasyonu
}

\author{
Mehmet Recai Durgut $^{1 *}$, Fuat Özbay ${ }^{2}$ \\ 1 Tekirdağ Namık Kemal Üniversitesi, Ziraat Fakültesi, Biyosistem Mühendisliği Bölümü, Tekirdağ, Türkiye (ORCID: 0000-0002-4780-5450) \\ 2 Özel Çerkezköy OSB MTA Lisesi, Tekirdağ, Türkiye (ORCID: 0000-0001-5725-5731)
}

(İlk Geliş Tarihi 12 Nisan 2020 ve Kabul Tarihi 23 Mayıs 2020)

(DOI: 10.31590/ejosat.718945)

ATIF/REFERENCE: Durgut, M R., \& Özbay, F. (2020). Mikroalgal Biyoyakıt Araştırmaları için Laboratuar Ölçekli Fotobiyoreaktör Otomasyonu. Avrupa Bilim ve Teknoloji Dergisi, (19), 221-226.

\section{$\ddot{O} \mathbf{z}$}

Bir fotobiyoreaktörün çalışması manuel olarak oldukça zordur. Fotobiyoreaktörün verimli çalışması, sistemden sık veri toplama yoluyla mümkün olan büyüme koşullarının yakın kontrolünü gerektirir. Manuel örnek toplama ve analizleri hem zahmetli hem de nispeten pahalıdır. Fotobiyoreaktörün verimli çalı̧̧ması için yapılan bu çalışmada; entegre bir gerçek zamanlı biyoreaktör izleme ve kontrol sisteminin geliştirilmesi, besin maddesi eklenmesi, biyokütle hasat zamanı, ışı, $\mathrm{CO} 2$ besleme döngüleri ve sıcaklık ile ilgili kararlar alınması, yosun oluşumu sırasında ekonomik kayıpların önlenmesi gerçekleştirilmiştir. Elde edilen sonuçlar göz önünde bulundurulduğunda yapımı gerçekleştirilen otomatik yetiştirme sistemi ile örnek alma, hasat ve besin ilavesi sırasında mikrobiyal kontaminasyonun minimuma indirildiği gösterilmiştir.

Anahtar Kelimeler: Fotobiyoreaktör, otomasyon, mikroalgal biyoyakıt, izleme sistemi.

\section{Laboratory-Scale Photobioreactor Automation for Microalgae Biofuel Research}

\begin{abstract}
It is really challenging to work a photobioreactor manually. Productşve working of the photobioreactor needs close check of growth conditions which is possible through continual data gathering from the system. Manual sampling gathering and analysis are both effortful and slightly expensice. In this work which is done for its efficient operation, the improvement of a combined actual-time bioreactor monitoring and management system, nutriment accession, time of the biomass collection, light, temperature-related decisions, furnishing cycles, preveting economic losses during algae formation were made. Considering the results, it's been shown that microbial contamination is minimized during sampling, gathering and nutriment accession along the programmed planting system.
\end{abstract}

Keywords: Photobioreactor, automation, microalgal biyofuel, monitoring system.

\footnotetext{
${ }^{*}$ Sorumlu Yazar: Tekirdağ Namık Kemal Üniversitesi, Ziraat Fakültesi, Biyosistem Mühendisliği Bölümü, Tekirdağ, Türkiye, ORCID: 0000-00027480-5450, rdurgut@,nku.edu.tr
} 


\section{Giriş}

Gelecekteki enerji taleplerini karşılama potansiyeline sahip alternatif enerji kaynaklarının geliştirilmesine ve toplumun fosil yakıta olan bağımlılığını azaltmaya büyük ilgi vardır. Dünya ekonomisi, çeşitli faaliyetler için fosil yakıtlara oldukça bağımlıdır. Dünya ekonomisinin en büyük enerji kaynağı petroldür. Bilindiği üzere petrol kaynaklarının azalması, insanlığı farklı enerji kaynakları arayışına itti. Pazar payı bu denli büyük ve değişken olan aynı zamanda işlenmemiş petrole ulaşımın kısıtlı olduğu bu ortamda petrole alternatif olacak kaynaklara talep oldukça arttı.

Biyodizel üretiminin bazı kısıtlayıcı noktaları vardır. Dünyamızda biyodizel elde edilen bazı bitkisel soylu fistık, kanola, aspir vb yağların gıda dalında da mühim bir hammadde olması, bunu kısıtlayan en önemli etmenlerden biridir. Bu nedenle, son yıllarda alglerden elde edilen yağlar biyodizel üretiminde kullanılmaya başlamıştır (Durgut, vd. 2015). Araştırmacılar, doğal su kaynaklarından mikroalg toplama ile ilgili problemler nedeniyle, yapay yuvarlanma havuzları, basamaklı açık sistemler ve kapalı sistemler gibi kültür yöntemleri geliştirdiler (Becker 1994, Richmond 2000).

Çeşitli kültür koşullarında mikroalg yetiştirme ve fizyolojik dinamikleri incelemek ve aynı zamanda kaynak kullanım verimliliğini optimize etmek için gerçek zamanlı bir izleme sistemi ve stratejisi uygulamak gereklidir. Mikroalg üretim ortamları için, biyokütle yoğunluğunun, mikroalglerin fizyolojik durumunun doğru ve zamanında ölçülmesi ve bunların, kültürün büyümesini ve ürünlerin kalitesini hassas bir şekilde kontrol etmek için geribildirim olarak kullanılması gereklidir (Puruhito 2014).

Bir fotobioreaktör için otomatik bir izleme ve kontrol sisteminin uygulanması, sürekli manuel ölçüm tekniklerinin ve yar1-sürekli veya sürekli veya aralık bazında gerekli verilerin elde edilmesi için gereken emek ihtiyacını ortadan kaldırır. Ayrıca, otomatik sistemin iyi kalibre edildiği ve muhafaza edildiği varsayılarak olası hatalar önlenebilir. Genel olarak, süreç, ürün ve çevresel kontrol önemli ölçüde geliştirilebilir ve elde edilen bilimsel araştırma ve verilerin değeri iyileştirilebilir.

Gerçek zamanlı panel tip fotobiyoreaktör kullanarak sistemimizin optimasyonunu ve verimliliğini arttırmaktır. Bütün bu faktörler gözönüne alındığında araştırma kapsamında, araştırmacıların gerçek zamanlı veri kaydı, izleme ve kontrol ile biyolojik araştırma yapmalarını sağlayacak kavramsal bir otomatik izleme ve kontrol sistemin tasarlanması hedeflenmiştir.

\section{Materyal ve Metot}

Araştırmada materyal hem açık sistemlere göre hem de diğer kapalı sistemlere göre daha kolay temizlenmesi, havalandırma işleminin daha kolay olması ve maliyetlerinin diğer sistemlere göre daha düşük olmasından dolayı panel tip fotobiyoreaktör kullanılmıştır (Richmond ve Zou 1999). Sistemde güç kaynağı olarak giriş değerleri 220V, çıkış değerleri ise $12 \mathrm{~V} / 5 \mathrm{~A} 60 \mathrm{~W}$ güç kaynağı tercih edilmiştir. Bunun yanında ana kontrolörü beslemek için LM2596 5V 30A çıkış verebilen ayarlı DC/DC dönüştürücü kullanılmıştır.

Gerçek zamanlı fotobiyoreaktör sisteminin teknik olarak tasarımı yapılırken Şekil 1'den faydalanılmıştır. Fotobiyoreaktör çalışması boyunca suyun sıcaklığı, elektrikli ısıtıcı yardımı ile mikroalg türünün yetiştirilmesi için optimum sıcaklık olan $25^{\circ} \mathrm{C}$ 'de sabit tutulmuştur (Zitelli vd. 2003, Dipasmita vd. 2011).

Sistemde pH ölçümü yapabilmek için DF Robot firmasının ürettiği E-900 pH probu ve amplifikatörü kullanılmıştır. Aydınlatma için 3000K yoğunluğunda harici beyaz LUXEON 5630 şerit led kullanılmıştır. 12 saat aydınlık, 12 saat karanlık olacak şekilde ayarlanmıştır. Aydınlatma panel tip fotobiyoreaktörün her iki yüzünden yapılmıştır. Yapılan çalışmalar her iki yüzden yapılan aydınlatmanın mikroalg yağ verimini \%14 artırdığını göstermiştir (Dipasmita vd. 2011, Doan ve Obbard 2011).

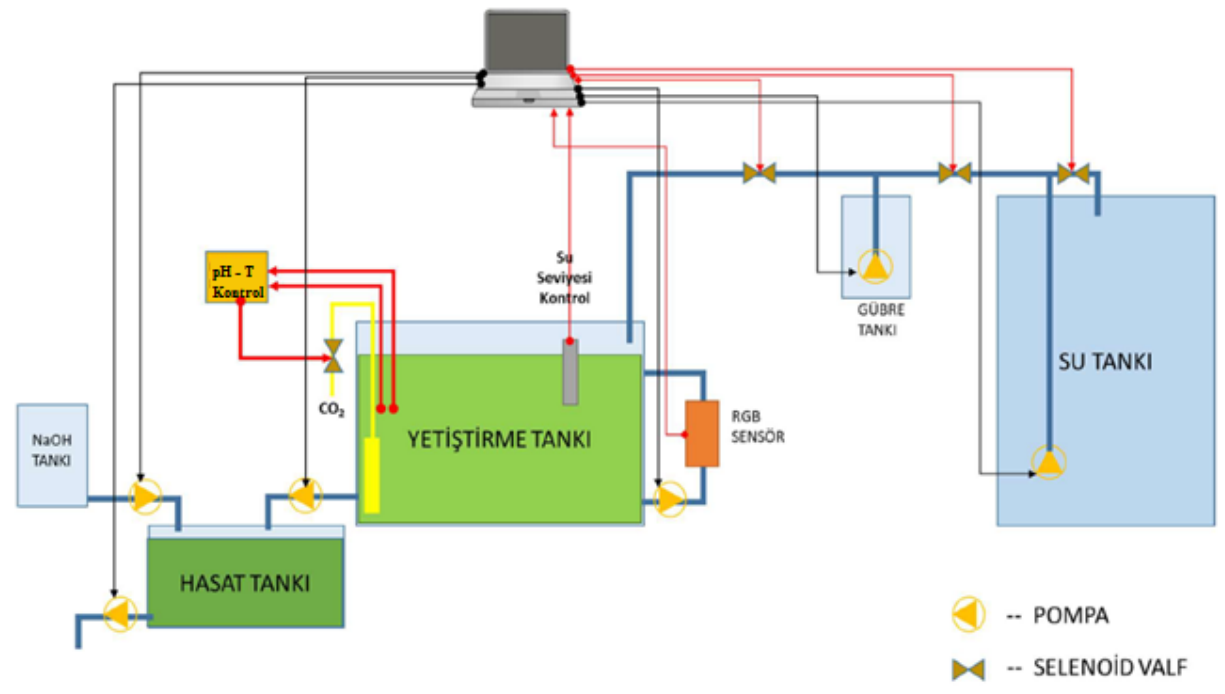

Şekil 1. Tasarımı yapılan otomatik kontrol sisteminin şematiği 
Ultrasonik sensör olarak HC-SR04 kodlu ürün kullanılmıştır. Bunun tercih edilmesinin sebebi sıvılarda ultrasonik dalganın daha etkin ve sağlıklı bir şekilde yansıtabilmesidir. Bu çalışmada, gerçek zamanlı fotobiyoreaktör sisteminde hasat zamanına karar verebilmek için rengi ölçebilen bir sensör sisteme entegre edilmiştir. Programlanabilen TCS3200 kodlu renk sensörü kullanılmıştır.

Sistemin kullanıcıya mesaj vermesi, bilgilendirmesi, gerçek zamanlı takibini yapmasını kolaylaştırıcı dokunmatik renkli ekran kullanılmıştır. Nextion grafik, renkli dokunmatik ekran tercih edilmiştir.

Tüm bu sistemin kısımları ana mikrodenetleyici üzerinden kontrolü sağlanmıştır. Sistem birden fazla kontrol yapısı içerdiğinden, Arduino Mega 2560 (ATmega 2560) mikrodenetleyici tercih edilmiştir (Nurrrahmawati ve Harmadi 2017). Ana kontrolörün yazılımına göre veriler, bir röle modülü üzerinde gruplara ayrılıp gerekli çıktıları vererek sistemin çalışmasını sağlamaktadır.

Peristaltik pompaları fotobiyoreaktör sisteminde, yetiştirme tankından renk ölçüm istasyonuna hasat zamanının karar verilmesi için mikroalglerin aktarımında, yetiştirme tankına gübre beslemesinde kullanılmıştır. Sistemde pH’ı sabit bir aralıkta tutabilmek için gerçek zamanlı ölçüm işlemi gerçekleştirilmiştir. Sistemdeki pH dengesini sağlamak için sisteme CO2 beslemesi yapılmıştır.

\section{Araştırma Sonuçları ve Tartışma}

Çalışacak olan tüm malzemelerin gerekli montajlarını sağlayabilmek için tasarlanan ürünlerde Solidworks 2018, tasarımların vücut bulması için ise Simplify3D programları kullanılmıştır. Prusa i3 tip 3 boyutlu yazıcı ile de tasarımı yapılan bu parçaların basımı yapılmıştır. Aynı zamanda elektronik kart tasarımı aşamasında ise Proteus 8,5 sürümü kullanılmıştır. Sistemin ana kontrolör yapısı için 12x18x9 mm uzunluklarında endüstriyel su geçirmez (IP 67) bir kutu kullanılmışırı (Şekil 2).

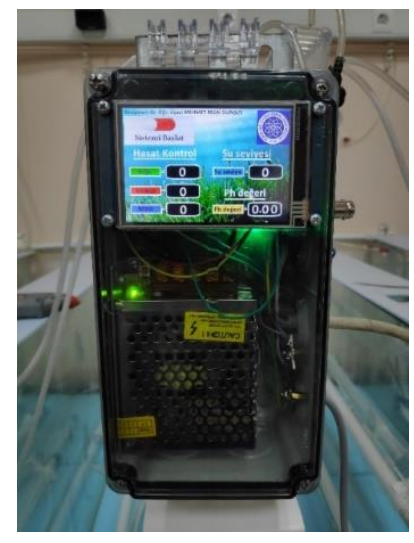

Şekil 2. Ana kontrolörlü endüstriyel kutu

Kullanılan TCS3200 sensörü, RGB renklerinin dalga boyları $($ kırmızı $=580 \mathrm{~nm}$, yeşil $=540 \mathrm{~nm}$ ve mavi $=450 \mathrm{~nm})$ dâhil olmak üzere $780 \mathrm{~nm}$ 'de bir tepe tepkisi ile 1şık spektrumunda epey hassastır (Jia vd. 2015). Bu hassasiyeti en aza indirebilmek için karanlık ortamdan oluşan bir hasat kontrol ünitesinden faydalanılmıştır (Şekil 3).

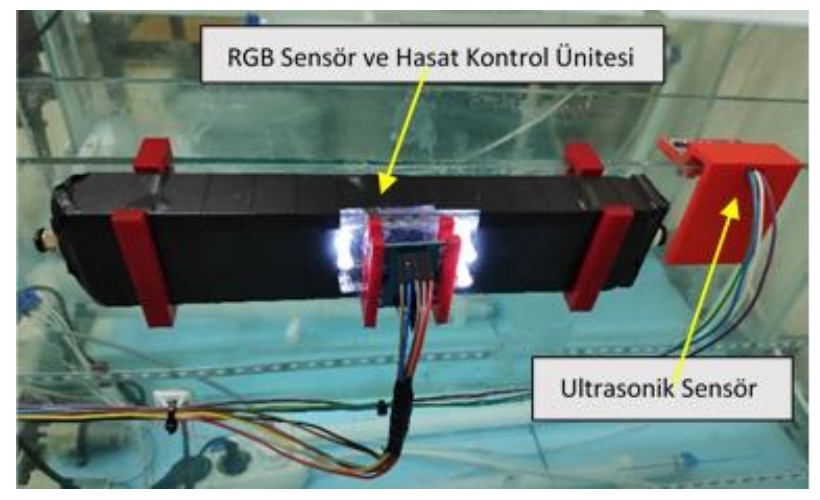

Şekil 1. RGB sensörünün algılama alanı

Algılama Alanı (Şekil 3), pleksiglas ile yapılmış optik ölçüm için uygun tasarlanmış 4 mm'lik bir test hücresinden oluşmuştur. Bu yapı içerisinden peristaltik pompa kullanılarak mikroalglerin sürekli olarak bu algılama alanının içerisinden geçirilerek ölçümler yapılmıştır. Sensör bir tarafta kullanımı tercih edilmiştir. Dışarıdan gelen ışı̆̆ın optik ölçüme zarar vermemesi için siyah ve ışık geçirmez bir kutu içerisine yerleştirilmiştir (Micaela vd. 2015). 
RGB renk ölçüm sensör ile mikroalglerin renk değişimini ölçerek hasat zamanına karar verildikten sonra hasat işlemi otomatik olarak başlatılmıştır. Hasat işlemi için yetiştirme tankından boşaltılan kültürün üzerine $\mathrm{NaOH}$ ekleyerek yosunun çökeltilmesi sağlanmıştır (Durgut vd. 2015, Keriş-Şen 2016).

$\mathrm{NaOH}$, hasat tankına verildiğinde çökelme başlatılıp, çökeltme işlemi bitirildiğinde ise pompa çalışarak hasat işlemi bitmiş döngüyü tamamlamış bir gerçek zamanlı sistem ortaya çıkacaktır. $\mathrm{NaOH}$ aktarım işlemi diyaframlı pompa ile yapılmaktadır.

Kullanıcı arayüzü ve bilgilendirilmesi için Arduino ile Nextion ekran seri haberleşme protokolüne bağlı olarak haberleşmektedir. Sistemde iki cihazın seri haberleşme baud rate (kanal hızı) 9600 olarak seçilmiştir (Bento 2018). Arduino ile Nextion arasındaki haberleşme prosesi kütüphanedeki seri haberleşme kesmesi protokolüne göre çalışmaktadır. Ekran üzerinde kullanıcıya sürekli olarak sistemin gerçek zamanlı bilgilendirilmesi yapılmaktadır.

Arduino içerisine yüklenen program şimdiye kadar araştırılan tüm bilgiler sentezlenerek ortaya çıkmıştır. Yazılımın açık kaynak kodlu olarak paylaşılması geliştirilmesi açısından oldukça önem arz etmektedir. Gerek içerisindeki yazılımın gerekse modül olarak kendisinin değişimi ve piyasada bulunurluk oranının da yüksek olması avantajları arasında gösterilmektedir.

Sistemde kullanılan 10'lu röle modülü sistemin çıktılarına göre görev yapan elemanların gerektiği anda çalışmasını sağlamaktadır. Röle modülü için elektronik kartın tasarımında deliksiz bakır plaket kullanılmıştır. Sistemin son hali Şekil 4 'teki gibidir. Verimliliği arttıran, laboratuvar tip, gerçek zamanlı fotobiyoreaktör sistemi gerçekleştirilmiştir.

Kullanılan HMI (Human Machine Interface) görevini üstlenen kapasitif dokunmatik ekranda sistemin ilk durum kontrollerinden nihai ürün çıkış aşamasına kadar olan ekran geçişleri kullanıcıyı yönlendirmede aktif rol oynamaktadır. Fotobiyoreaktör ilk kez enerjilendiğinde Şekil 5 ’teki ekran görüntülenmektedir.

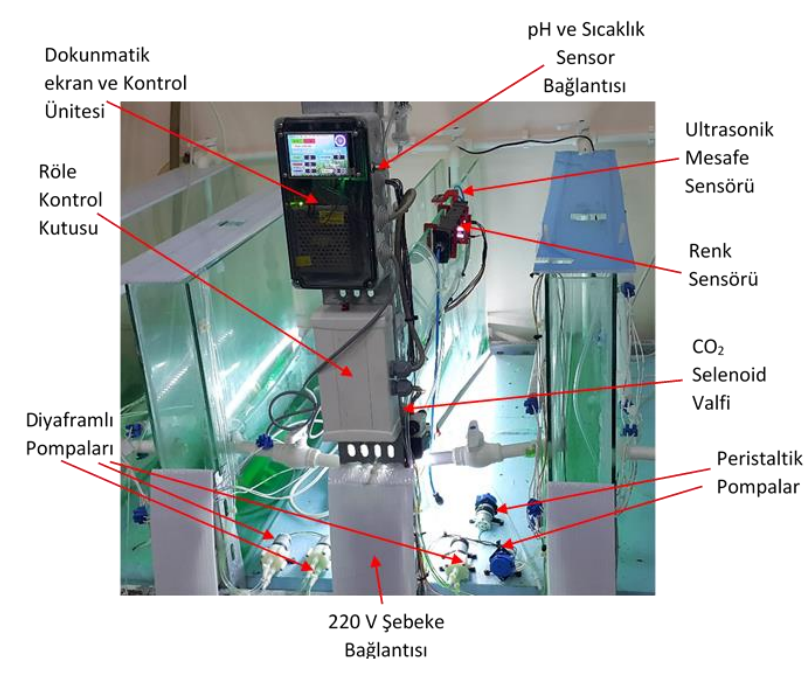

Şekil Hata! Belgede belirtilen stilde metne rastlanmadı.. Fotobiyoreaktör sisteminin genel görünümü

Ekranda sistem Start butonu ile başlatılmaktadır. Stop butonuna basıldığında ise hemen durmamakta, bir döngülük işlemi bitirip prosese bu işlem sonunda son vermektedir.
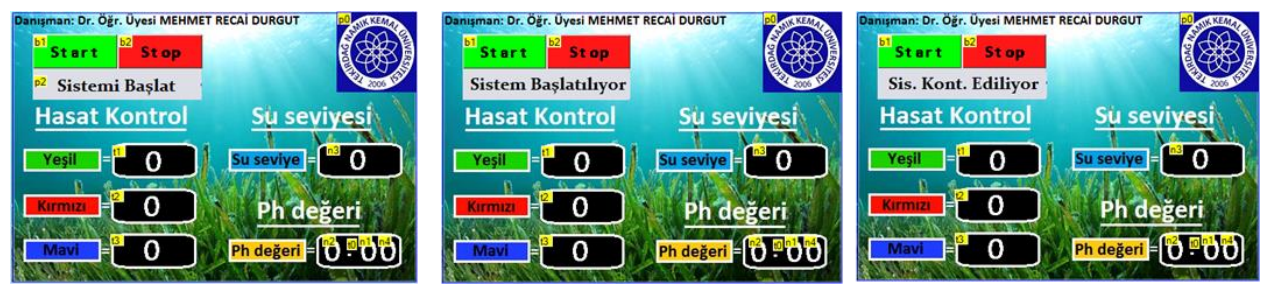

Şekil 5. Başlangıç ekranı, sistem başlatılıyor ve kontrol ediliyor ekranları

Sistem iki ana algoritmadan oluşmaktadır. İlki start butonuna basıldığında bir defaya mahsus tüm veriler (Su seviye durumu, $\mathrm{pH}$ değeri ve renk algılaması) mikrodenetleyici olarak kullanılan Arduino Mega içerine çekiliyor ve sırası ile ekrana transfer edilmektedir. İkincisi ise her 5 dakikada bir yine tüm verileri kontrol edip karar yapısından geçirerek sistemi sürekli izlemektedir.

Start butonuna basıldıktan hemen sonra sistem başlatılıyor ve sistem kontrol ediliyor yazıları ekranda kullanıcıyı bilgilendirmektedir. Sistem kontrol algoritmasına ilk olarak yetiştirme tankındaki su seviyesini kontrol ederek başlar. Su seviyesine karar verdikten sonra durumu kullanıcıya ekranda bilgi olarak gösterir. Su seviyesi yetersiz ise su eklemesi yapar eğer su seviyesi yeterli ise bir sonraki kontrol algoritmasına geçiş yapar.

Eğer yetiştirme tankının içerisindeki su yetersiz sisteme su alınıyor ekranı çıkacaktır. Sürekli ölçülen su seviyesi istenen değere ulaştı̆̆ında Su seviyesi normal yazısı kullanıcıyı su seviyesi hakkında bilgilendirecektir. 
Su seviye algoritmasını bitirdiğinde $\mathrm{pH}$ seviyesini kontrol eden algoritma işlevsel hale gelerek fotobiyoreaktörün içerisindeki pH değerini algılayıp kullanıcıya ekran yardımı ile bilgilendirir. pH kontrol edildiğinde 8 biriminin üzerine çıktığında $\mathrm{CO} 2$ girdisinin başlatıldığını gösterir. $\mathrm{pH}$ değerini normal seyrine geçene kadar $\mathrm{CO} 2$ aktarımı durdurulmaz. $\mathrm{pH}$ değeri ölçüm sonucu normal aralığına düştüğünde ise $\mathrm{pH}$ değeri normal bilgisini vererek bir sonraki karar algoritması olan yosun kontrol prosesine geçiş yapar.

$\mathrm{Ph}$ değer ölçümünün akabinde hasat kontrol karar algoritması devreye girmektedir. Bu algoritmada sistem RGB ölçüm kapsülüne peristaltik pompa yardımı ile yetişme tankındaki karışımı aktarım yapmaktadır. Bu aktarımı tamamlayabilmesi için motor 10 saniye boyunca çalıştırlıp renk ölçümü yapılmaktadır. Renk ölçümü sonrasında renk hazır değilse bir sonraki karar algoritmasına geçecek, renk hazırsa hasat için hasat karar algoritmasına geçiş yapacaktır.

Eğer hasat için karar verilmemiş ise ekranda Sistem Stabil yazısı görünecektir. Bu aşamaya gelindiğinde sistem $5 \mathrm{dk}$ boyunca bekleyecektir. Bu sürenin sonunda ilk karar algoritması olan su kontrolünü gerçekleştirerek aynı sırayı izleyerek otonom çalışmasını sürdürecektir.

Tasarlanan algoritmaya göre 5 dakikalık ara ile tüm bu fonksiyonları tekrar tekrar çalıştıracaktır. Yosunun hazır olduğuna otonom olarak karar veren otomasyon kullanıcıya "Yosun Hazır” bilgisini ekran üzerinden ulaştıracaktır.

Yosun hazır bilgisini alan mikrodenetleyici hasat başlama algoritmasını çalıştıracaktır. Bu algoritmanın içeriğinde ise yetişme tankındaki mikroalgleri diyaframlı pompa yardımı ile hasat tankına aktaracaktır. Hasat tankına tamamının aktarıldığını su seviye kontrol sensörü algılayacaktır. Tamamı aktarıldıktan sonra hasat tankına $\mathrm{NaOH}$ ekleyerek hızlı çökertme başlayacaktır. Tüm bu işlemlerin sonunda ekranda ekranda "Sistem Başlat" yazısı belirecektir ve "Çökertme Başladı" bilgisinin görüntülenmesinden sonra kullanıcıdan sistemi tekrar başlatması istenecektir.

\section{Sonuç}

Otomasyon sistemlerinin malzeme pahalıllğı bunların fotobiyoreaktör sistemlerinde kullanım oranlarını maalesef en az seviyeye çekmektedir. Bu durumun önüne geçebilmek ve zirai alanlarında da otomasyon sistemlerinin kullanımını arttırabilmek için ucuz ve kaliteli üretim yapılmalıdır. Güncellenen sistemlerde bu durum aşılmaktadır. En önemlisi ise teknik personelin bu gibi sistemlerde etkin rol oynamasıdır. Teknik personelin yetiştirilmesi ve bu alanda tutulabilmesi yaygınlaştırılmasında büyük engel olarak karşımıza çıkmaktadır.

Endüstri 4,0'ın en önemli özelliği kişiselleşmiş ürünlerin ortaya çıkarılmasıdır. Bunun yanında sistemlerin kolaylaştırılarak ve duru hale getirilerek herkesin kullanabileceği düzeye indirgenmesidir. Bunu esas alarak tasarlanmış bu sistem, kullanıcı dostu yönlendirilmeler ile sistemin herkes tarafından anlaşılır ve kullanılabilir duruma getirilmesi hayali ile planlanmıştır. Sistemin bir özelliği de dokunmatik ekran ile durumun anlık bilgilendirilmesi ve kontrolüdür. Bu kullanıcı için karmaşıklı̆̆ı ortadan kaldırabilmektedir.

Tasarım aşamasında sistemde kullanılan sensörler, hassas çalışmaktadırlar. Ortam değişkenlerine bağlı olarak ölçümlerde sürekli farklılık göstermesi sistemin başlangıç kalibre ayarlarını değiştirmekte ve zorlaştırmaktadır. Sistemin başlangıcında bu ayarların doğru kurularak sisteme entegre edilebilmesi gerekmektedir.

Fotobiyoreaktör sisteminin tüm teknolojik aletleri seçilirken kolay bulunabilmesine, kolay montajlanabilmesine ve uygun fiyatı olmasına dikkat edilerek seçilmiştir. Sistem elemanlarının birbirleri ile uyumlu çalışılabilmesi için mikrodenetleyicili, yani yazılım içerikli bir ana kumanda sistemi tercih edilmiştir. Diğer kontrol cihazları tak çıkar mantığı üzerine kurulmuştur.

Sistem tabanının veriyi kolaylıkla değiştirilebildiği bir ortam tasarlanmıştır. Bu sayede sistemin sürekli güncellenebilmesi, yeniliğe açık olabilmesi sağlanmıştır. Bunun yanı sıra verimliliği temel almış bir fotobiyoreaktör olarak planlamıştır. En az girdi ile en çok çıktı alabilmek ana hedeflerden biri olarak alınmıştır. Yosunun verimliliğini arttırıcı müdahaleler sistem tarafından programa uygun olarak yerinde ve zamanında yapılacak şekilde uygulanmıştır.

Sistem her ne kadar en yeni teknolojiler ile tasarlanmış olsa da, laboratuvar tip olduğu düşünüldüğünde bazı kısıtll1ıklar ve bunları aşmak için farklı yöntemler tercih edilebilir. Bunlardan biri sistemin anlık bilgilerinin ekranda görüntülenebildiği gibi kablolu veya kablosuz olarak internet ortamında da istenildiği yerden gerek kişisel bilgisayarlardan gerekse cep telefon aplikasyonundan da ulaşılabilir. Sistemde kullanılan algılayıcıların tamamı kablosuz hale getirilebilir. Bu pratiklik ve oluşabilecek arıza, bakım işlemlerinde kolaylık sağlayabilir. Sistem verileri sürekli kayıt edilerek geçmişe dönük mikroalg kültür denetimi ve takibi yapılabilir. Gübre tankındaki solüsyonu yine burada kullanıldığı gibi peristaltik pompalar yardımı ile sistem ihtiyaç duyduğunda karışımı kendi hazırlayabilir. Hasat tankına hasat olunan mikroalglerin yağ kütle ölçümleri yapılıp kullanıcı yine dokunmatik ekran üzerinden bilgilendirilebilir.

\section{Bilgi /Teşekkür}

Bu makale Fuat Özbay'ın 2019 yılında Tekirdağ Namık Kemal Üniversitesi, Fen Bilimleri Enstitüsünde yayınlanan Yüksek Lisans tezi'nden faydalanarak hazırlanmıştır. 


\section{Kaynakça}

Becker, E.W. (1994). Microalgae: Biotechnology and Microbiology. Cambridge University Press, Cambridge.

Benavides, M., Mailier J., Hantson A. L., Muñoz G., Vargas A., Impe J. V. ve Vande A. (2015). WouwerDesign and Test of a Low-Cost RGB Sensor for Online Measurement of Microalgae Concentration within a Photo-Bioreactor, Sensors 15, 4766-4780; doi:10.3390/s150304766.

Bento, A. (2018). IoT of Nextion X TFT ILI9341. International Research Journal Of Engineering, IT \& Scientific Research, 4(2), 1423. doi:10.21744/irjeis.v4i2.624.

Dipasmita, P., Goldberg I. K., Cohen Z. and Boussiba S. (2011). The effect of light, salinity, and nitrogen availability on lipid production by Nannochloropsis sp. Applied Microbial And Cell Physiology 90:1429-1441. DOI 10.1007/s00253-011-3170-1

Doan T.Y. ve Obbard J. P. (2011). Improved Nile Red staining of Nannochloropsis sp. J Appl Phycol 23:895-901, DOI 10.1007/s10811010-9608-5.

Durgut M.R., Aktaş T., Kayişoğlu S. ve Yağcılar Ç. (2015). Mikrodalga Yöntemiyle Mikroalg Yağından Biyodizel Üretiminde Optimum Reaksiyon Koşullarının Belirlenmesi, Namık Kemal Üniversitesi, Bilimsel Araştırma Projeleri, Proje No: NKUBAP.00.24.AR.14.08

Jia, F., Kacira M. ve Ogden K. L. (2015). Multi-Wavelength Based Optical Density Sensor for Autonomous Monitoring of Microalgae, Sensors, 15, 22234-22248; doi:10.3390/s150922234.

Keriş-Şen, Ü. D. (2016). Mikroalglerin Sudan Ayrıştırılmasında Ve Biyoetanol Üretiminde Ozon Ve Ultrases Kullanımı, Doktara Tezi, Gebze Teknik Üniversitesi.

Nurrrahmawati, A. ve Harmadi, H. (2017) Rancang Bangun Alat Ukur Konsentrasi Oksigen yang Dihasilkan oleh Fotobioreaktor Mikroalga Chlorella vulgaris Menggunakan Sensor SK-25F, Jurnal Fisika Unand Vol. 6, No. 3.

Puruhito, E. (2014). Automated Monitoring and Control Systems for an Algae Photobioreactor, Master Thesis, Arizona State University.

Richmond, A. ve Cheng-Wu, Z. (2000). Optimization of a flat plate glass reactor for mass production of Nannochloropsis sp. outdoors, Journal of Biotechnology 85: 259-269p.

Richmond, A. ve Zou, N. (1999). Effect of light-path length in outdoor flat plate reactors on output rate of cell mass andof EPA in Nannochloropsis sp., J Biotechnol, 70: 351-356p.

Zitelli, G.C., Rodolfi L. ve Tredici M.R. (2003). Mass cultivation of Nannochloropsis sp. in annular reactors. Journal of Applied Phycology 15: 107-114. 